Supplementary Materials

\title{
Explanation of Methods
}

\section{Temperature calculation}

Temperature is calculated by the integration of equation (1) together with the flow velocity $q_{z}$ of groundwater. To evaluate $q_{z}$ we follow Manga and Rowland (2009) by approximating $q_{x}$ in equation (3) with an averaged head gradient between the fault zone and the discharge zone:

$$
q_{x}=-K_{H} \frac{d h}{d x} \approx-K_{H} \frac{h_{o}-h}{D}
$$

where $K_{H}$ is the horizontal conductivity of the aquifer outside the fracture zone, $h_{o}$ the head at the discharge end of the aquifer and $D$ the horizontal distance to the discharge end. Replacing $q_{x}$ in (3) by (S1) we have

$$
\frac{S_{y}}{L} \frac{\partial h}{\partial t}=K_{V} \frac{\partial^{2} h}{\partial z^{2}}+K_{H} \frac{h_{o}-h}{w D} .
$$

This equation is identical to equation (2) in Manga and Roland (2009) with the specific storage $S_{s}$ replaced by $S_{y} / L$. The solution for $h$ and the corresponding vertical discharge $q_{z}$, under the boundary conditions of $h=0$ at $z=0$ and $\partial h / \partial z=0$ at $z=L$, are given by equations (6) and (7) in Manga and Roland (2009). The solutions for $q_{z}$ at depth intervals of $1 \mathrm{~m}$ and time intervals of 1 hour are inserted into a finite-difference scheme (S3) to integrate (1) for $T$, starting from the temperature profile before the earthquake.

$$
\begin{gathered}
T\left(z_{i}, t\right)=T\left(z_{i}, t-d t\right)+d t^{*} \kappa *\left[T\left(z_{i+1}, t-d t\right)-2.0 * T\left(z_{i}, t-d t\right)+T\left(z_{i-1}, t-d t\right)\right] /\left(d z^{*} d z\right) \\
-0.5 * d t^{*} \gamma * q_{z}\left(z_{i}, t\right) *\left[T\left(z_{i+1}, t-d t\right)-T\left(z_{i-1}, t-d t\right)\right] / d z
\end{gathered}
$$

\section{Estimate modeling parameters}

The effective horizontal permeability for the aquifers at the upper rim of the alluvial fan, composed of gravels and coarse sands intercalated with marine mud, is given by

$$
K_{H}=\frac{1}{L} \int_{0}^{L} K(z) d z
$$

where $L$ is the saturated thickness of the layered sequence. It is controlled by the layer with the highest conductivity and an average value of $\sim 10^{-4} \mathrm{~m} / \mathrm{s}$ is estimated from well tests (Tyan et al., 1996). Baseflow recession analysis of stream discharge (Wang et al., 2004a) shows that $K_{H}$ did not change after the earthquake.

On the other hand, the effective vertical conductivity $\left(K_{V}\right)$ of the sequence changed after the earthquake. Before the earthquake, $K_{V}$ is given by 


$$
K_{V i}=\left[\frac{1}{h} \int_{0}^{L} \frac{d z}{K(z)}\right]^{-1}
$$

and is controlled by the layer with the lowest conductivity (i.e., aquitards); an average value of $\sim 10^{-8} \mathrm{~m} / \mathrm{s}$ is estimated from lithological logs and tabulated conductivity measurements. After the earthquake, the aquitards were breached by vertical fractures; the new effective vertical conductivity, $K_{V f}$, may be estimated from the post-seismic 'recession' of the water level in wells (Wang et al., 2004b), with an average value of $\sim 10^{-5} \mathrm{~m} / \mathrm{s}$. A specific yield $S_{y} \sim 0.2$ is estimated for the sandy and gravelly aquifer (Fetter, 2001, Table 3.5). Finally, we approximate the width of the fracture zone $w \sim 10 \mathrm{~km}$ from the distribution of wells that showed a coseismic drop of water level (Wang et al., 2001). The distance to the discharge zone $D \sim 10 \mathrm{~km}$ is based on postseismic recession analysis (Wang et al., 2004b). The basement depth $L$ is likely to vary from well to well; we use $L=300 \mathrm{~m}$ to include all wells listed in Table S1. The parameters so estimated constitute the "reference model" and are listed in Table 1.

\section{References}

Fetter, C.W., 2001, Applied Hydrogeology, $5^{\text {th }}$ edition, Upper Saddle River, N.J., Prentice Hall.

Manga, M., and J.C. Rowland, 2009, Response of Alum Rock springs to the October 30, 2007 earthquake and implications for the origin of increased discharge after earthquakes, Geofluids, v. 9, p. 237250.

Tyan, C.L., Y.M. Chang, W.K. Lin and M.K. Tsai, 1996, The brief introduction to the groundwater hydrology of Choushui River Alluvial fan, in Conference on Groundwater and Hydrology of the Choshui River Alluvial Fan, Taiwan, Water Resources Bureau, p. 207-221 (in Chinese).

Wang, C.-Y., L.-H. Cheng, C.-V. Chin, and S.-B. Yu, 2001, Coseismic hydrologic response of an alluvial fan to the 1999 Chi-Chi earthquake, Taiwan, Geology, v. 29, p. 831-834.

Wang, C.-Y., Wang, C.H., and M. Manga, 2004a, Coseismic release of water from mountains: Evidence from the $1999(\mathrm{Mw}=7.5)$ Chi-Chi, Taiwan, earthquake, Geology, v. 32, p. 769-772.

Wang, C.-Y., C.-H. Wang, and C.-H. Kuo, 2004b, Temporal change in groundwater level following the $1999(\mathrm{Mw}=7.5)$ Chi-Chi earthquake, Taiwan, Geofluids, v. 4, p. 210-220. 